\title{
Hormonal Transduction of Environmental Stresses
}

\author{
Schuyler Seeley \\ Plants, Soils and Biometeorology Department, Utah State University, Logan, UT 84322-4820
}

The evolutionary axiom "survival of the fittest" presumes universal stresses. Stress is the result of any constraining force or influence that limits normal growth and development. No earthly organism has ever lived its life cycle out without a stress burden. Stresses are erratic, unevenly cyclical, and ever-changing, so that avoidance of stresses for the production of today's crops may or may not be successful for the next month or the next year. Through aeons of time plants have developed under natural stress conditions. Adaptation allowed survival:

Climate is the set of generalizations resulting from the assembling, analyzing, and summarizing of long-term weather records. The complex of environmental variables - temperature, radiation, precipitation, humidity, wind, and soil factors-to which a plant is exposed is the microclimate. All elements of the microclimate interact simultaneously and constantly on the plant during each stage of its growth and development and the plant environment must be described in terms of all influencing factors. While the plant reacts immediately to the current microclimatic environment, its genome is the result of adaptations to a much longer history of changing microclimates.

Simple annual plants have evolved so that their growth and development coincide with a favorable microclimatic growth period that allows progression through the plant life cycle. The simplest case would be a plant in a continuously favorable microclimate for seed germination, development, growth, maturation, seed production, and seed dispersal. The cycle would continue as long as such a plant remained in the favorable microclimate. When the plant experienced less-than-optimum environmental conditions (stress) after relocation from the ideal microclimate, through seed or plantlet dispersal or through climatic changes, survival was low. After considerable time for adaptation, development of mutant plants that could survive in the less-than-optimal environment occurred. Adaptations, such as rosette formation and the requirement for a cold period between the rosette and seed formation phases enabled survival under adverse conditions. Biennials resulted.

Eventually, temperate zone plant seeds and buds gained the capability to carry the germplasm of the plant through rather long, adverse microclimatic periods before conditions conducive to germination were again favorable for the next development and growth period. The various bud and seed dormancy systems (Berrie, 1984; Kahn, 1982) reflect the diversity of control that separate plants or plant families developed during their evolution.

Perennial plants developed the capability to survive cyclically adverse microclimatic conditions. They developed specialized leaves that could protect the growing points and withstand an unfavorable environment and evolved into the deciduous condition, with leaf bases becoming the shelter for dormant growing points in "winter" buds. Growth cessation, winter bud scales, layers of exuded protectants, dehydration, and other adaptive mechanisms developed.

During early evolutionary development, as in the development of biennials from annuals and perennials from biennials, certain well-established physiological adaptions developed. Dormancy developed as an an adaptation to stress. This developmental phenomenon probably occurred rather early on the evolutionary scale. It was such an important physiological development that it was retained in seeds and buds of later, more-complex plant forms.

In today's advanced agriculture, many stresses have been relieved, resulting in abundant harvests. In the even more advanced crop physiology of those plants that have been grown in chambers, with everything optimized for growth and food production, stresses have been minimized. The research goal has been to produce plants suited for such environments to maximize yield. Indeed, yields of specially bred wheat in such chambers now approach $68 \mathrm{t} \cdot \mathrm{ha}^{-1}(\mathrm{~B}$. Bugbee, personal communication), and continuous cropping is possible. Culture of these crops in the field, however, would probably result in crop failure.

In many cases, plants have been taken from their evolutionary niches to climates (colder or warmer, wetter or drier) in which moresevere and extraordinary stresses have been imposed. Special cultural practices have been developed in those areas to allow plant survival and fruit production. It is in these areas where the greatest increases in productivity may be made with greater understanding of plant stress physiology.

The fruit tree growth season takes place from late winter to early 
summer during the period of lowest stress. In all other seasons, stress levels are relatively high and limit plant growth. Stress of the endodormancy system may occur during winter if temperatures are too high or too low for extended periods. Deciduous fruit tree growth systems are activated by temperature in late winter and early spring. Promoter hormone levels increase dramatically just before bloom and then decline gradually to minima in early summer. High temperature stress during bloom or early fruit growth may result in blossom or fruit abscission. Water stress at any time in the growing season may severely limit growth and development.

Four examples of stresses and their effects on hormones governing growth and development of orchard trees will be considered in this paper: 1) the effects of temperature stresses on the transition from endodormancy to the ability to grow, 2) the effects of stresses during early spring growth, 3 ) the effects of multiple stresses on shoot growth cessation, and 4) the effects of water stress on hormone-directed assimilate partitioning between shoots and fruit of peach trees.

\section{Hormonal transduction of endodormancy release}

The fruit tree year, according to the Utah Chill Unit Model (Richardson et al., 1974), begins on 1 Sept. A summation of chill units is recorded daily to measure development of the endodormancyreleasing chilling process necessary in fruit trees to preserve them through a thermally adverse portion of their life cycle and to prepare them for development and growth. The isothermal temperature response curve for the chilling mechanism in peaches is given in Fig. 1A. In cool temperate-zone climates, negation temperatures $(>15 \mathrm{C})$ do not usually occur during the late fall and winter and are not important in the chilling process. Chill unit accumulation is negative in late summer until average temperatures go below the chill negation/chill accumulation threshold, From that time, chill units accumulate to satisfy the chilling requirement. The chilling process depends on bud or seed temperature, and a chill unit is defined as $1 \mathrm{hr}$ at the optimum chilling temperature at the optimum chilling time. At other temperatures and times, fractional chill units accumulate. Seeds and buds of each fruit tree species are comparable in their temperature response characteristics (Seeley and Damavandy, 1985; Pasternak and Powell, 1980). Development of a temperature response surface for buds would be a formidable research problem; therefore, the temperature response surface (Fig. 1B) used for peach buds is one that was developed from studies with peach seeds (Seeley and Damavandy, 1985). Chilling requirements are characteristic of cultivars and are determined genetically (Westwood and Bjornstad, 1968; Thompson et al., 1985).

In cold and in warm climates, temperatures below and above the chilling range-may prolong the chilling process. These adverse temperatures could be characterized as stresses to the chilling process. Chill unit accumulation curves from a cold climate often show a plateau during the coldest winter months and vary from year to year due to temperatures. below the chilling range (Fig. 2). As a result, completion of the required chilling occurs later in the following late winter or spring. At the other extreme, temperatures in warm climates frequently are in the chill negation range and reverse the effect of previously accumulated chill units (Erez et al., 1979). Frequently, chilling requirements are not completed and delayed foliation follows, a condition that results in abnormal growth and low yields (del Real-Laborde, 1987).

Terminability of seeds and budbreak of shoots are not accurate indicators of endodormancy status. Seed germination or budbreak may result from microclimatic or manipulative stresses of the seed or bud without. further growth. The results of insufficient chilling stress or incomplete endodormancy development in buds and seeds may be partially observed in delayed budbreak and poor seed germination. They are more clearly seen in delayed foliation of buds. In seeds, they maybe observed in the anatomy of physiologically dwarfed seedlings. Study of germination, seedling emergence, and physiological dwarf symptoms gives a more complete characterization of the endodormancy-releasing chilling process than germination alone. Observations of such stress-induced abnormalities give clues about the physiology of chilling.
Physiological dwarfing may be due to the presence of inhibitors, absence of promoters, inadequate synthesis of biochemical pathways, or inadequate phase change, resulting in only partial DNA transcription or translation. Changes in the endodormancy system in peaches are cumulative. Unchilled seeds always produce dwarfs, seeds chilled partially at 5C produce semidwarfs, with size depending on the amount of chilling, and fully chilled seeds produce normal plants (Flemion, 1956).

Physiologically dwarfed seedlings produced in several of our experiments during the past few years have shown symptoms of auxin (IAA), gibberellin (GA), and cytokinin (CK) deficiencies such as reduced vascular growth in leaves (epinasty), abnormal cell division and differentiation in leaves (epinasty), small leaves, achlorophyllous leaves, shortened internodes, absence of lateral roots, and curtailed root elongation growth. Many delayed foliation symptoms are similar. Symptom severity in physiological dwarfs and in delayed foliation decreases with increased chilling. These anatomical clues indicate that the machinery for auxin, gibberellin, and, possibly, cytokinin synthesis is activated slowly during chilling and that several mechanisms are involved. Furthermore, it appears that it is the machinery for synthesis of growth promoters and not the promoters per se that are produced during the period of chilling (Powell, 1987). Thus, the results of the stress of insufficient chilling in comparison to complete chilling reveals some possible physio-

\section{A}

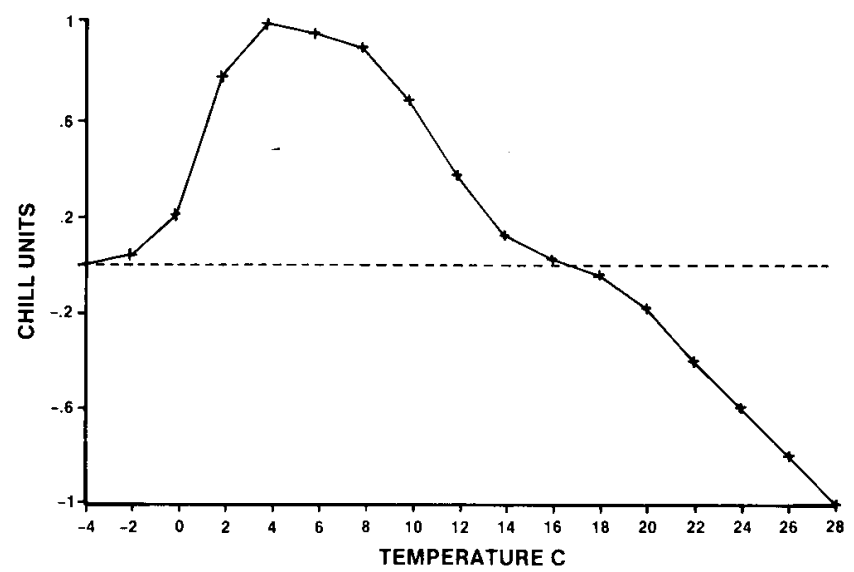

B

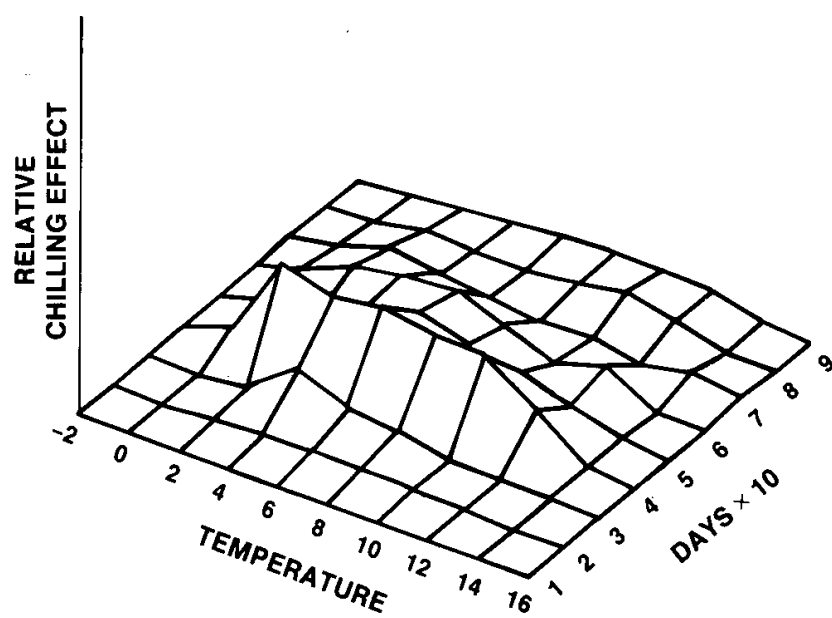

Fig. 1. (A) Isothermal temperature response curve for chilling of 'Elberta' peach buds. One hour at $4 \mathrm{C}=1$ chill unit. Temperatures $>16 \mathrm{C}$ reverse the process. (B) Temperature/time response surface for 'Elberta' peach seed chilling. One hour at 4 to $10 \mathrm{C}$ at 40 days $=1$ chill unit. Fractional chill units accumulate at higher and lower temperatures and carlier and later times. 


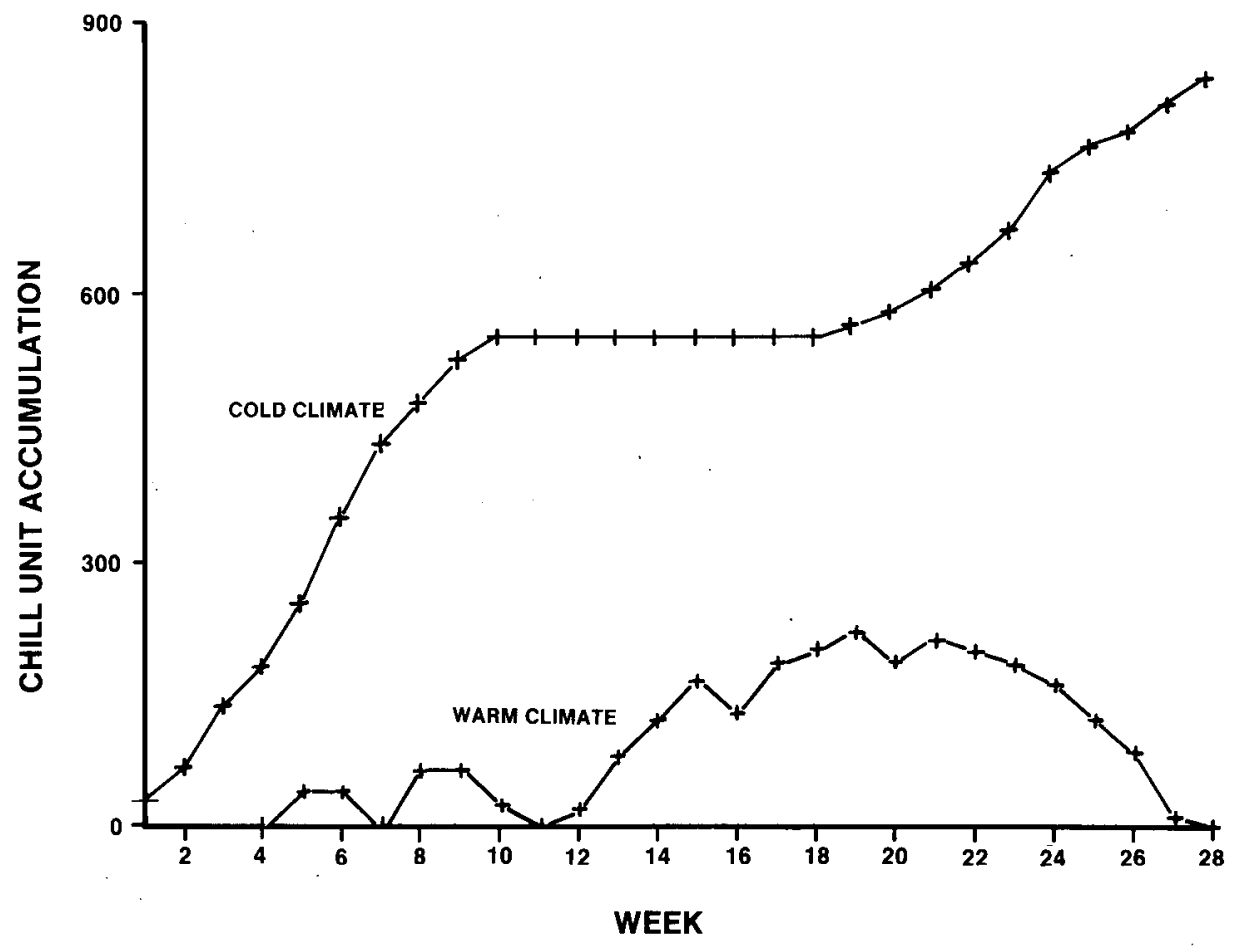

Fig. 2. Chill unit accumulation in a climate in which temperatures during the 12 th to the 19 th week wcre below $-2 \mathrm{C}$ and not effective in chilling and in a warm climate in which high temperatures result in negation of previously received chilling.

logical drivers of the phase change from endodormancy to the ability to grow. Possible hormonal roles in physiological dwarfs as indicated by symptomology are given in Table 1 .

Characteristics of the chilling temperature curve that propels the development of winter endodormancy release are known. However, no specific biochemical mechanism that fits the curve has been isolated and characterized. It appears that the inhibitor abscisic acid (ABA) may reinvolved in endodormancy induction, but not in endodormancy release. Some evidence exists that auxin may play a role in endodormancy release. Substantially more evidence exists that gibberellins and cytokinins are involved (Powell, 1987). Specific details of the hormonal-transduction of effectual temperatures on the endodormancy release mechanism remain to be elucidated.

\section{Stress during spring growth}

In cool climates, the chilling requirement is completed before average temperatures rise above the threshold for flower and vegetative bud development. Often, a late winter brings a short period of warm temperatures, and species that have completed their chilling requirements begin to grow and deharden. High or low root temperatures from this period until bloom are ineffective in accelerating or delaying bloom. Anthesis depends on air temperature (Hammond and Seeley, 1978). Therefore, evaporative cooling may be used to delay bloom (Anderson et al., 1975).

Control of shoot growth is directed by the basipetal translocation of IAA in cambial initials and mother cells through formation of xylem and phloem when interacting with gibberellins (Wareing, 1958; Wareing et al., 1964) and through hormone-directed mobilization of plant metabolizes and hormones from the shoots and nutrients and cytokinins originating in the roots. Bennett and Skoog (1938) were able to show that, during chilling, "a precursor of auxin" accumulated in the buds followed by the gradual appearance of auxin. Active growth depends on a continuous supply of basipetally transported IAA (Little and Wareing, 1981; Digby and Wareing, 1966; Avery et al., 1937; Richardson, 1959; Hatcher, 1959). Cytokinins are important in the shoot tips and lateral cambia for cell division. Gibberellins are thought to exert their physiological effects through auxin-mediated mechanisms (Wareing and Phillips, 1978).
Table 1. Hormonal roles in physiological dwarfs of apple and peach.

\begin{tabular}{lllll}
\hline \hline \multicolumn{3}{c}{ Hormone $^{2}$} & \\
\cline { 1 - 2 } Auxin & Gibberellin & Cytokinin & Ethylene & Physiological process \\
\hline $\mathrm{X}$ & $\mathrm{X}$ & & Cell division \\
$\mathrm{X}$ & $\mathrm{X}$ & & Cell enlargement \\
$\mathrm{X}$ & & $\mathrm{X}$ & Vascular differentiation \\
$\mathrm{X}$ & $\mathrm{X}$ & $\mathrm{X}$ & Leaf expansion \\
$\mathrm{X}$ & $\mathrm{X}$ & $\mathrm{X}$ & Stem growth \\
$\mathrm{X}$ & & $\mathrm{X}$ & Achlorophyllous streaking \\
$\mathrm{X}$ & & $\mathrm{X} ?$ & Apical dominance \\
$\mathrm{X}$ & & Epinasty \\
$\mathrm{X}$ & & & No terminal root growth \\
$\mathrm{X}$ & & & No lateral root growth \\
\hline zX indicates a hormonal role in the physiological processes responsible for \\
physiological drawfing.
\end{tabular}

In most trees, the general sequence of activity in late winter or early spring is a) auxin production, b) bud swell, c) basipetal auxin movement, d) auxin-directed transport, e) bark peelability, f) root growth, g) cambial divisions in the apical meristem, h) descending cambial divisions, i) phloem differentiation, and j) xylem differentiation.

The seasonal pattern of auxin production in apple shoots has been documented by two groups. Increasing concentrations were found from the tight winter bud in March to a maximum just after shoot growth started. Auxin concentration then declined as shoot growth progressed, and reached a minimum at terminal bud formation (Avery et al., 1937; Hatcher, 1959). The shoot tip may contain less auxin than the leaves, nodes, and internodes lower in the shoot (Hatcher, 1959; Zimmerman, 1936). But, the control of growth remains in the shoot tip, because decapitation causes a rapid decline in yield of diffusible auxin in all parts of the shoot below (Zimmerman and Brown, 1974).

The phonological thermal accumulation required for first swelling of flower buds can be measured in growth units (GU), equivalent to $1 \mathrm{hr}$ at the optimum cardinal temperature for growth. For 'Montmorency' tart cherries, 954 chill units are required before effective thermal accumulation begins. The first swelling stage of tart cherry 
flower buds requires $127 \mathrm{GU}(22 \%)$ of the 566 required for full bloom. During this GU accumulation to first swell, physiological changes occur. Buds that are in control of the cambial activity of the tree begin to produce auxin and gibberellins when exposed to suitable temperatures (Little and Wareing, 1981; Seeley, 1975). Roots, however, are not thought to have the same type of chilling requiring endodormancy as the top of the plant, but are under the control of active buds when no leaves are present in the early spring (Richardson, 1959). Numerous authors have found actively growing tree roots during winter, but the activity may have been found after the chilling requirement of the top had been completed (no distinction between endodormancy and ecodormancy was made in these studies).

Roots of silver maple (Acer saccharinum L.) have a temperature threshold for growth between 2 and $5 \mathrm{C}$, while the threshold for shoot growth is between 5 to 10C (Richardson, 1959). The shoot growth threshold for orchard species is $\approx 5 \mathrm{C}$. More than a century ago, the ambient temperature control of growth was documented when it was noted that trees on south-facing sites could complete one-fourth of their cambial activity 30 days before trees on northfacing sites only 100 paces away began their cambial activity (R. Hartig, as cited by Zimmerman and Brown, 1974, p. 85).

Some authors have indicated that there is a widening temperature range for growth in late winter and spring. A widening of the temperature range for budbreak was shown graphically by Vegis (1964); a more recent study by Rom and Arrington (1966) indicates that relatively low temperatures were more conducive to growth of peach trees in the early spring than were higher temperatures. Their interpretations of the widening temperature range and the superior effects of low temperatures over high temperatures in early springtime growth may have been due to inexact methods of determining the endodormancy status of experimental plants. In cold and warm climates, the chilling requirement to complete endodormancy often terminates late in the winter season. Experiments done late in the dormant period would indicate a low temperature optimum, because the optimum cardinal temperature for endodormancy completion is between 0 and $8 \mathrm{C}$. This chilling process must be completed before trees gain the capability to grow. Our recent studies with apricot, peach, apple, and cherry all indicate that, after the chilling period has been completed, the growth responses to temperature follow a normal sigmoid curve, beginning at the effective low threshold temperature for orchard species and reaching an optimum at or above
25C. High temperatures that occur during the dormant period may negate previous chilling and even cause secondary endodormancy. However, temperatures in the normal growth range given after endodormancy is complete are not stressful.

Cytokinins produced in the roots and translocated to the shoot through the newly differentiated vascular tissues are mobilized along the auxin gradient toward the shoot tip and are used for cell division in the active growing regions. When the shoot is decapitated by pruning or browsing stress, regeneration of the physiological tip occurs. While this is happening, apical dominance is reduced enough to allow several lateral buds to break because of the loss of auxindirected polar distribution of cytokinins that diffuse into nodes that ordinarily would not contain high concentrations. Once regeneration of the physiological tip has occurred, the newly growing apices once again establish apical dominance. Low-temperature stress sufficient to cause bud death during this time will significantly delay the activation of the tree. Water stress during this time will result in increased levels of endogenous ABA in the phloem-cambial region of bark peelings and decrease the basipetal movement of IAA through branch sections (Little, 1975).

\section{Hormonal transduction of stress during shoot growth cessation}

Apple tree IAA (Avery et al., 4937; Hatcher, 1959) and CK (Luckwill, 1970) have been found in highest concentrations during bloom. Promoter concentrations decline gradually and reach very low levels at about the time of shoot growth cessation in midsummer. Abscisic acid concentrations in fruit trees increase throughout the summer (Seeley and Powell, 1981) (Fig. 3). In contrast, IAA levels in Sitka spruce (Picea sitchensis Bong.) do not decrease at the end of the growing period, but the ability to respond to IAA does (Little and Wareing, 1981, Zajaczkowski, 1973). Little and Wareing (1981) point out that, in Sitka spruce, the springtime initiation of activity is correlated with increases in IAA from buds. However, two indicators, bark peeling immediately below a girdle placed during ecodormancy and vigorous cambial activity in several species that were completely disbudded, show that renewed growth can be supplied with IAA originating from storage areas and not originating from terminal buds. Similarly, they cite three lines of evidence that the entrance into the dormant condition does not depend on a decrease in the IAA supply: 1) IAA production and

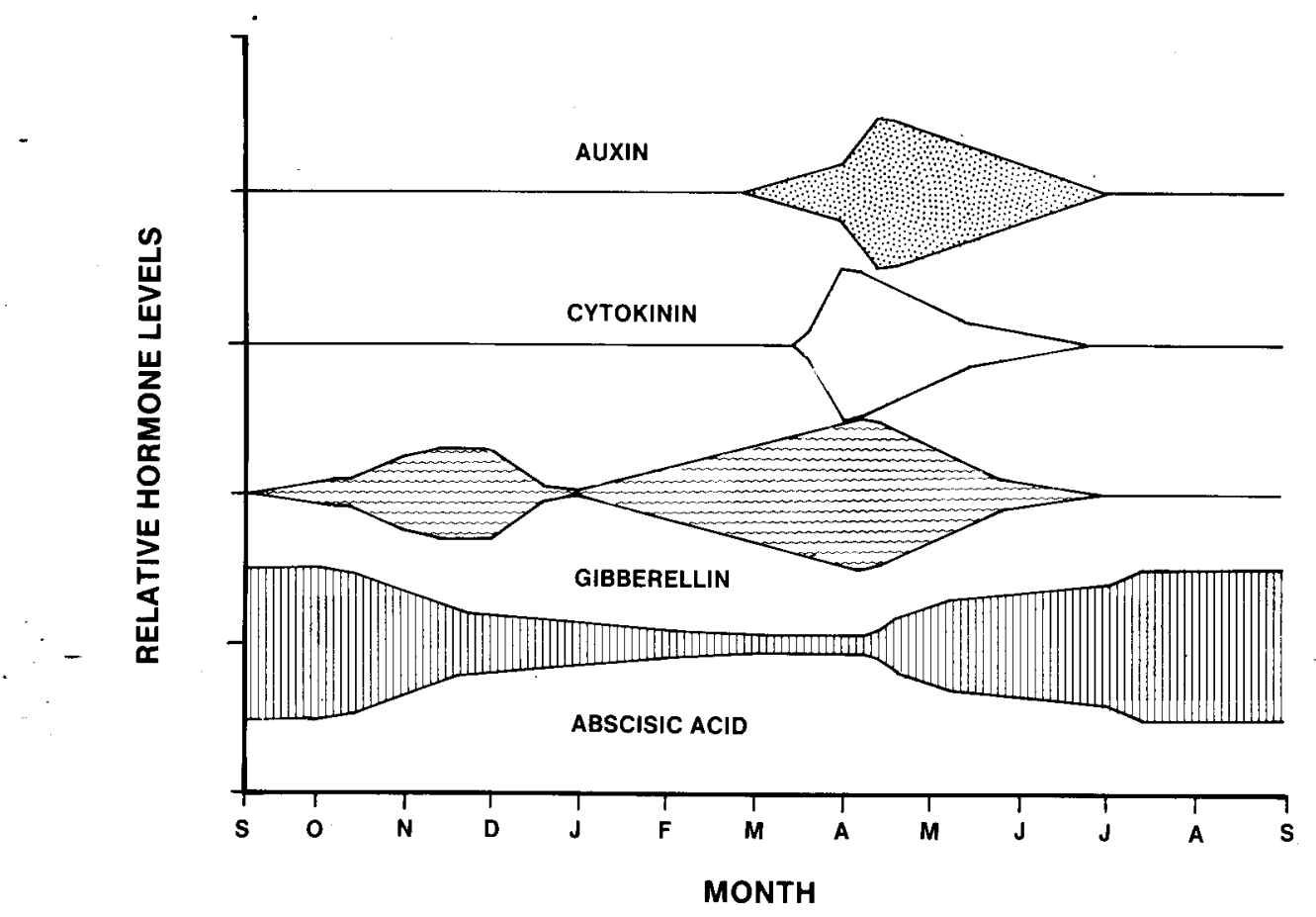

Fig. 3. Parallel variations among auxin, cytokinins, gibberellins, and abscisic acid during the annual cycle of growth and developmient in deciduous fruit trees. Auxin and cytokinin data from Luckwill (1970), abscisic acid data from Seeley and Powell (1981), Gibberellin data from Seelcy (1975). 
concentration depends on environmental characteristics in all seasons; 2) cambial rest develops regardless of IAA levels; and 3) responsiveness of cambium during endodormancy varies from a low at maximum endodormancy to a peak when the cambium is fully quiescent, although transport of IAA is similar in the two stages. Little and Wareing conclude that, in spruce, the gradation from endodormancy to growth and the transition from growth to endodormancy do not depend on changes in auxin concentration, but may depend on sensitivity to IAA. Thus, it appears that shoot growth control in conifers depends on sensitivity to the promoter IAA, while, in orchard trees, the control of shoot growth is governed by declining promoter levels.

The flush of shoot growth in the tree appears to be regulated by auxin arising in the apical bud or lateral cambia of the shoot. The annual ring of wood in tree trunks and shoot growth may be controlled by sensitivity to auxin because concentration does not vary appreciably in the stem in conifers (Wodzicki, 1971) and it is probably controlled by supply in orchard trees (Avery et al., 1937; LuckWill, 1970). Some control other than IAA supply is implicated in endodormancy, because Reinders-Gouwentak (1941) found that auxin did not influence dormant tissues. Apparently, other hormones or sensitivity may be involved.

During the early summer, climatic conditions become unfavorable for growth. Soil and air temperature and radiation levels are high. Photoperiod is long and relatively unchanging. Relative humidity and soil moisture levels reach mid-day and seasonal lows, especially in unirrigated orchards. Nutrient levels, especially nitrogen, are at their minima. High water potentials in the tree trigger decreased IAA and increased ABA production. Growth stops. Dormancy may be released, although with increasingly diminished growth capacity, by relieving these stresses. Growth of the uppermost lateral bud after terminal bud removal may be used as an indicator of the transition from ecodormancy to endodormancy (Seeley and Powell, 1981). After shoot growth cessation in apple and spruce, applications of IAA will not induce renewed growth. However, applications of gibberellin will induce vegetative budbreak, but not flower budbreak, in peaches throughout their dormant period (Hatch and Walker, 1969).

Actual (Hatcher, 1959) (Fig. 4) and simulated (Little and Wareing, 1981) (Fig. 5) drought during growth will induce temporary ecodormancy in trees. These droughts are characterized by elevated ABA and decreased IAA content, but are followed by subsequent recovery and growth when the stress is relieved. Little (1975) has shown that internal water stress in Abies balsamea L. Mill. inhibits cambial activity through reduced photosynthesis and transpiration, reduced auxin-driven cambial activity, and inhibited auxin translocation. He found that internal water stress increased ABA and decreased auxin in the phloem-cambial region.

As long as promoter hormones are present in the shoot, the growthretarding effects of $\mathrm{ABA}$ are masked and growth continues. It is only after promoter hormones decrease to low levels that the ABA

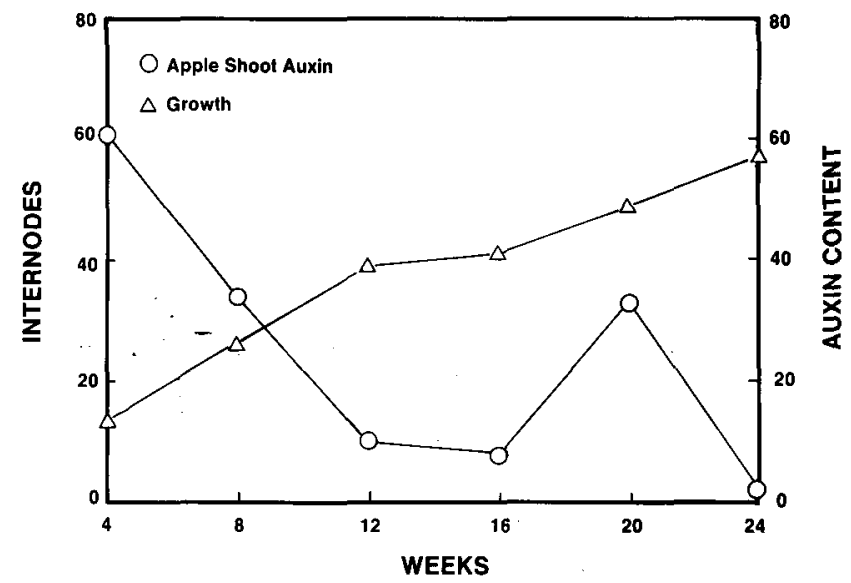

Fig. 4. Drought stress effect on apple shoot growth and corresponding auxin content. Data from Hatcher (1959). effect on growth can be observed. Inhibitor/promoter ratios may be important in shoot growth cessation. Or, it may be possible that sensitivity to the various hormones changes in the plant sometime during the late summer. ABA, in the absence of significant promoter hormone levels, may be the hormonal transducer of environmental stresses during endodormancy induction.

\section{Hormonal transduction of water stress in assimilate partitioning}

Irrigation has been used to control peach tree shoot growth and fruit productivity through its effect on endogenous hormones. The shoot growth curve is sigmoid, while fruit growth has been shown to follow a double-sigmoid growth curve that includes an initial exponential phase (stage I), a lag phase during pit hardening (stage II), and a final exponential enlargement and ripening phase (stage III) (Connors, 1920). Irrigation studies have shown that tree water requirements increased slowly as shoot and fruit growth began, reached maximum levels during mid-season, and declined after harvest (Evans, 1982).

Fruit growth has been found to be in direct competition with growth of the tree frame and root. While the tree was young, the proportion of dry weight partitioning into fruit was around $30 \%$. As tree age increased, increased proportions (up to 70\%) of dry weight were partitioned into fruit. The proportion of dry weight going into the frame and roots decreased from around $40 \%$ and $20 \%$ to less than $10 \%$ and $1 \%$, respectively. The ratio of top growth to root growth increased from 1 to 4 as the tree went from juvenility to old age (Chalmers and van den Ende, 1975). Therefore, it may be possible to manage the young tree to redirect growth from shoots to fruit.

Each of the two primary sinks, shoots and fruit, competes for assimilates present in the tree during growth, but the fruit is the stronger competitor (Chalmers and van den Ende, 1977). Hormone levels [IAA, Powell and Pratt (1966); GA, Jackson (1968)] have been related to various stages of fruit growth (Fig. 6). Promoter hormone levels are significantly higher in the fruit than in the shoot, giving a hormone-directed transport advantage to the fruit. Stressinduced $\mathrm{ABA}$ production in young shoot leaves regulates growth there, while the fruit is relatively immune to reduced growth because of abscisic acid action until assimilate production is reduced. Even when the tree is under stress, the fruit continues to draw assimilates at the expense of other parts of the tree.

Water stress has been shown to stop shoot and leaf growth immediately (Acevedo et al., 1971). When the stress was relieved after a short time, the plant resumed its normal growth rate and recovered the increment of lost growth. Longer periods of stress result first in cessation of vegetative and then fruit growth. Fruit have the capacity to deplete current assimilates during periods of stress if the fruit water potential was not low enough to prevent cell expansion. A balance exists between the water demands of the fruit and shoot growth and this balance changes depending on the current status of water demand by the fruit (Chalmers and Wilson, 1978).

Chalmers et al. (1981) have shown that, when irrigation is reduced in high-density peach orchards during the pit-hardening stage, shoot growth was terminated with little or no effect on fruit growth during the applied stress. Thereafter, fruit growth continued with significantly reduced water and assimilate competition from shoots. They found yield increases of up to $30 \%$ when high-density plantings were stressed to limit shoot growth and increase subsequent fruit growth (Fig. 7).

ABA is the primary water stress-transducing hormone. Water stress results in elevated leaf ABA levels (Wright and Hiron, 1969). $\mathrm{ABA}$ acts to close stomates and conserve water in the leaf and also increases the permeability of root tissue to water (Glinka and Reinhold, 1972). Stomatal closure may exist long after ABA levels return to normal (Mansfield, 1987). Water stress also results in decreased cytokinin levels in the transpiration stream (Mizrahi, 1980). Long-term control of shoot growth occurs when IAA and CK levels have reached mid-summer lows and ABA levels are enhanced by stress. Fruit hormone levels remain high and their status contributes to their competitive advantage. 

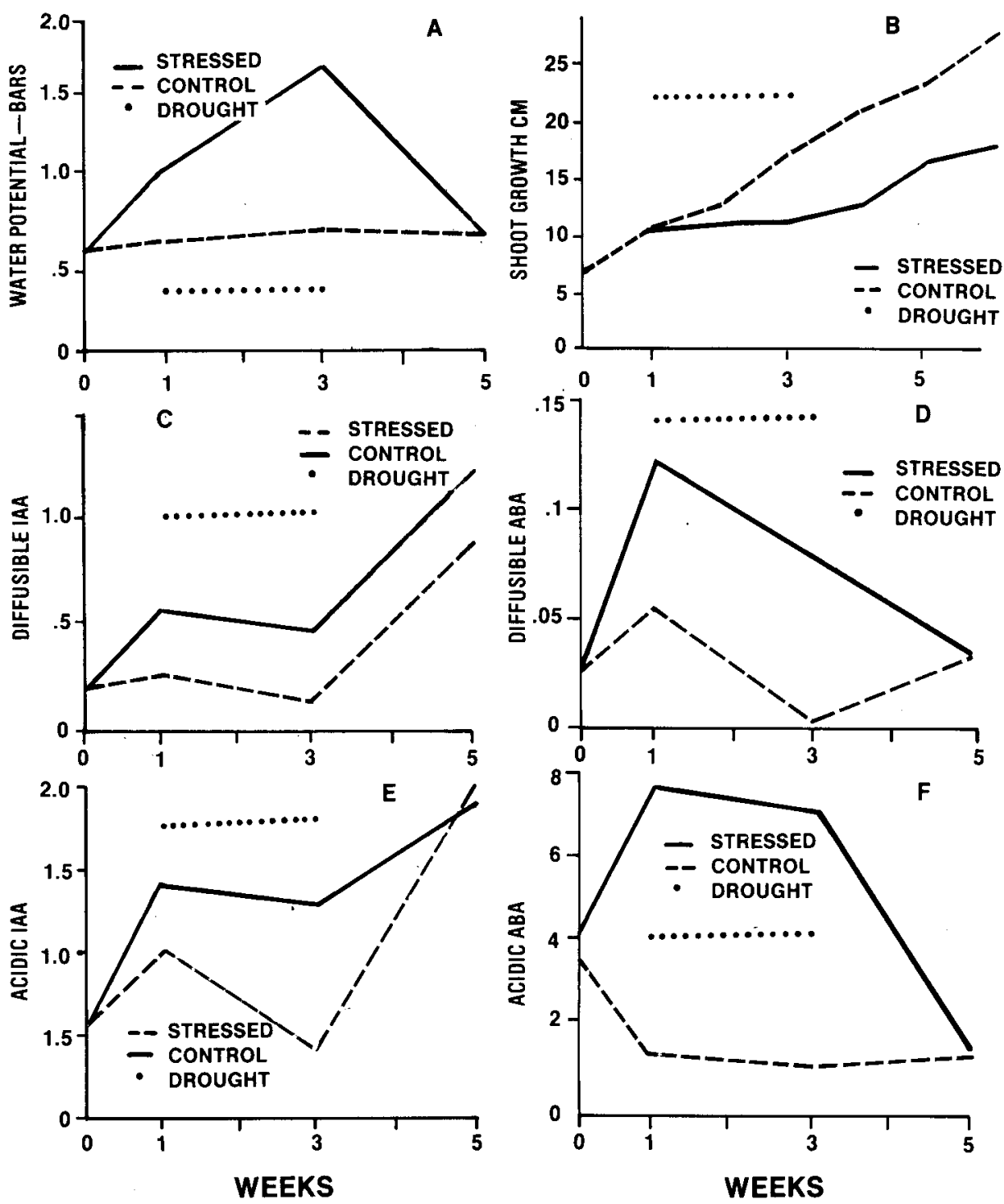

Fig. 5. Simulated drought effect on xylem water potential (A), the current year's shoot growth (B), diffusible IAA (C), diffusible ABA (D), acidic IAA (E), and acidic ABA (F) of the cambial region of the previous-year's terminal shoots of Picea sitchensis Bong. Drought stress duration ( (...). Data from Little and Wareing (1981).

Therefore, stresses maybe applied to the orchardist's advantage. Carefully applied irrigation strategy for young, high-density peach trees, may induce drought stress. This stress may actually be used to stop shoot growth through elevated ABA and decreased promoter hormones and result in increased fruit production.

\section{General roles of hormones in stress}

Auxin is the directing shoot growth hormone. It moves basipetally from growing shoot tips and expanding leaves and acropetally from root tips and, through effects on mobilization and directed transport of other hormones, nutrients, and metabolizes, maintains control of where growth occurs in shoots and roots. It also has partial control over stomate opening, root and shoot elongation, lateral root and shoot formation, xylem differentiation, cambial activity, ethylene production, and cell division. Its production in shoots and basipetal movement in areas where the effects of water stress, defoliation, pruning, browsing, wind, pollution, salt accumulation, nutrient deficiencies, and toxicities are critical, allows it to exert long-term control over tree growth and development.

Cytokinins are produced in root tips and exert partial control over many shoot functions, such as cell division, chloropiast development, leaf expansion, stomatal opening, lateral bud growth, leaf epinasty, wound healing and leaf senescence. Stresses such as nitrogen deficiency, drought, waterlogging, erosion, exposed roots, root pruning, rodent damage, inhibited aeration, and low soil temperature cause decreases in cytokinin production and the manifestation of low cytokinin concentrations in the trunks and lateral shoots of trees.

The relative production of auxin and cytokinins by shoots and roots regulates the shoot : root ratio. This ratio changes during the life of the tree; it is near unity during juvenility and then increases slowly throughout the mature life of the tree. Stress on the tree or the roots that results in damage or necrosis brings about an imbalance in the tree and the resulting surplus of auxin or cytokinin causes invigoration of the hormone target portion of the plant. The very large leaves and extensive shoot growth of a plant that has been killed back to the ground by a freeze and the branching of trees in nurseries under optimum growth conditions are the result of a high cytokinin : auxin (root : shoot) ratio.

Gibberellins are growth-promoter hormones that stimulate plant systems. Cell and internode elongation, seed germination, and fruit set and growth are GA effects. In general, plants with high vegetative GA levels are succulent and susceptible to stress.

Abscisic acid and ethylene are the direct stress transducer hormones. ABA causes stomatal closure in many plants at about -1.0 $\mathrm{MPa}$ water potential. The balance of ABA, IAA, and CK may be responsible for precise rapid control of stomatal movements in response to changing environmental characteristics. ABA synthesized in shoots may be translocated to the root and increase the perme- 


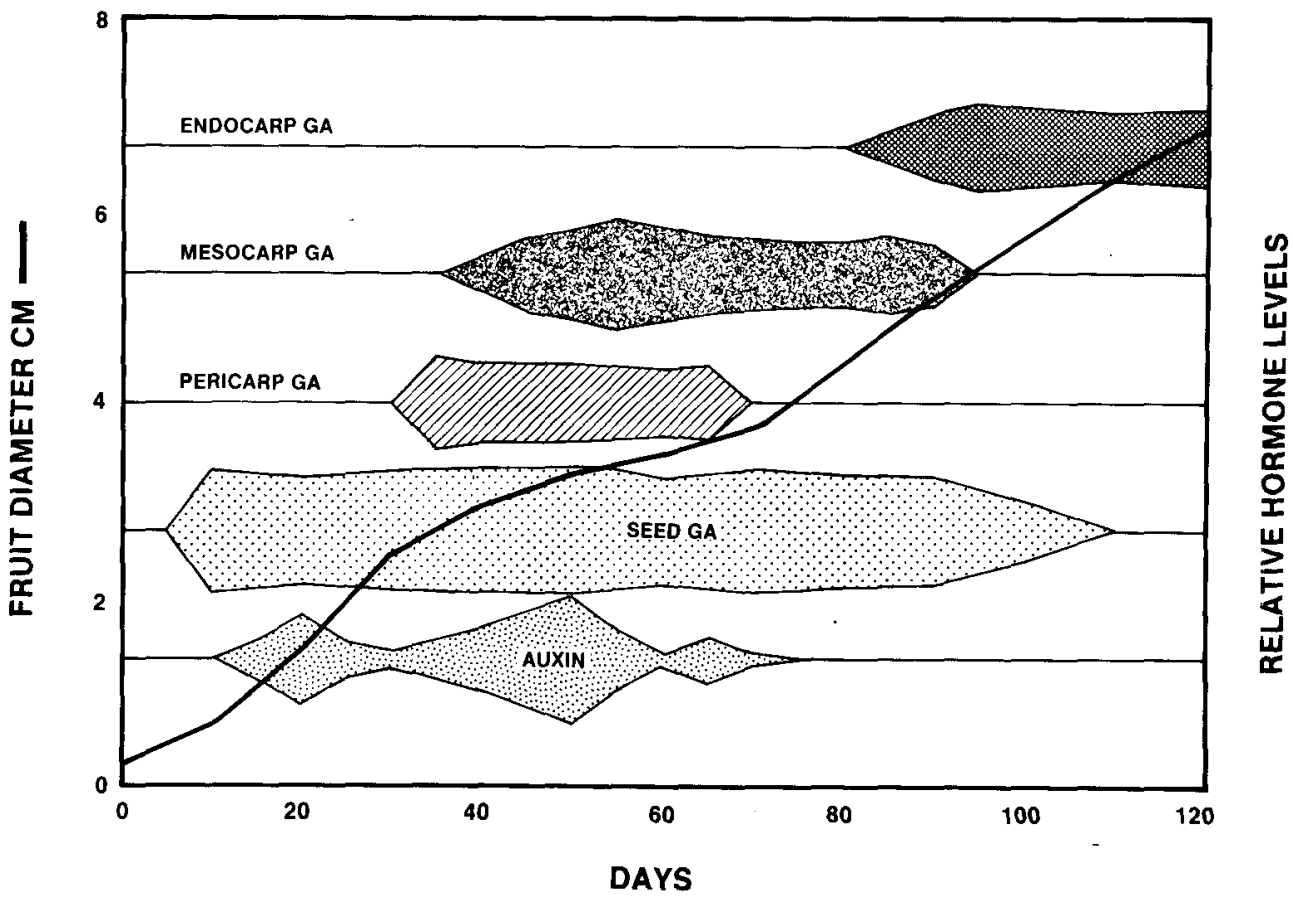

Fig. 6. Parallel variations among peach seed auxin and seed and flesh gibberellin in relation to fruit growth. Auxin data from Powell and Pratt (1966). Gibberellin and fruit size data from Jackson (1968). All data normalized to 120 days of fruit growth.

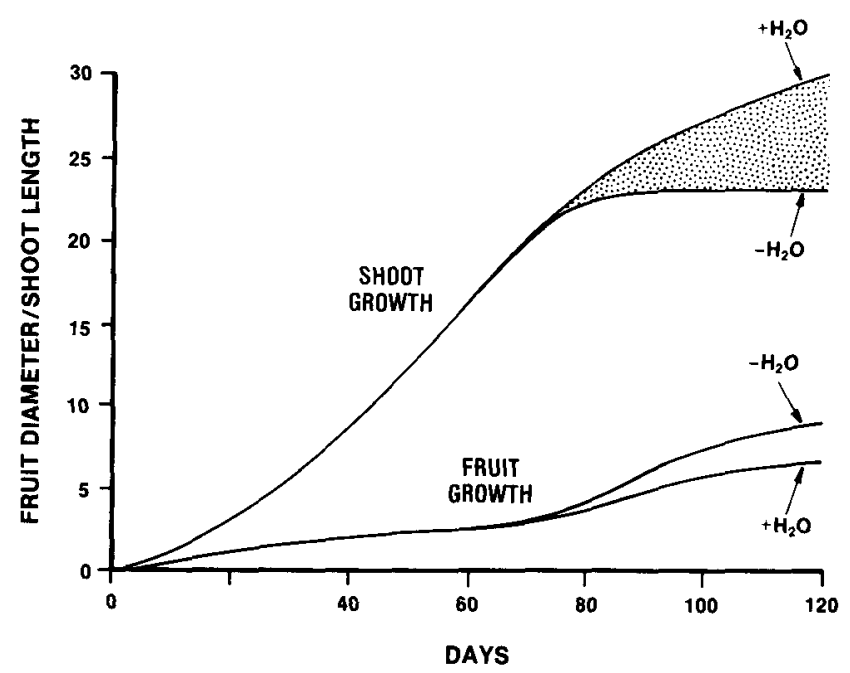

Fig. 7. Stage II drought stress effect on shoot growth and fruit growth of young high-density-peach trees.

ability of root tissue to water. Leaf growth is limited and shoot : root ratios decrease under stomatal closure conditions.

Abscisic acid may play roles in the cessation of shoot growth in mid-summer and the development of endodormancy. The combination of low levels of growth-promoting hormones, root growth cessation, reduced nutrient uptake, high root and shoot temperatures, high radiation levels, low relative humidity, and full canopy development result in significant water stress during mid-summer in temperate-zone climates and may play a role in terminal growth cessation, vegetative maturity, and winter bud formation. There are indications that sensitivity of the plant to some promoter hormones changes during the transition from growth to quiescence and later to endodormancy. However, other plants may rely on changes in hormone concentrations for these developmental changes. The endodormant condition increases gradually during late summer and reaches a peak in the fall. Thus, the change from the grand phase of growth to preparations in the plant for fall and winter may be transduced by an increase in stress-induced inhibitor hormones.
Ethylene production increases in response to physical stimuli and root flooding. Wounding of or application of ethylene to Prunus spp. results in stimulation of gum production, a typical stress response. Severe drought stress results in ethylene-induced leaf abscission that may preserve the plant through periods of stress.

\section{Conclusions}

Plant stresses have been ubiquitous in evolutionary development. In being so, they have become integral in the regulation of plant growth and development. This dependence on stressful environmental cues for development has provided plant scientists with a broad base of stress-related genes.

Phase change (endodormant to active, active to endodormant) in perennial plants is not understood fully. However, it is probable that phase changes are initiated by environmental cues and that those cues are transduced by plant hormones such as IAA, GA, ABA, $\mathrm{CK}$, and ethylene. Culture of horticultural plants in adverse microclimates requires phase change facilitating cultural practices. Models of plant growth and development that have clearly identified driving forces can expedite physiological research by serving as estimators of phase change.

Temperature stress during winter in the form of extreme cold or unseasonable high temperatures results in inadequate chilling of perennial fruit trees, which causes delayed foliation and reduced fruit production. Development of promoter synthesis systems that are thought to be responsible for spring growth may be interrupted by such stressful temperatures.

Stresses during spring and summer due to root growth cessation, nutrient deficiency, drought, high evaporative demand, high root and shoot temperatures, high radiation levels, low relative humidity, and full leaf canopies result in shoot growth cessation. High ABA levels occur concurrently with low IAA, GA., and CK levels under such conditions. Drought stress during the growth period causes increased $\mathrm{ABA}$ and decreased IAA and $\mathrm{CK}$, which may result in earlier than normal shoot growth cessation, smaller canopies, and smaller than normal trees.

Suitably imposed drought stress during summer in young highdensity irrigated peach trees can be used to divert allocation of plant resources from vegetative growth into fruit growth, producing larger harvests. This is possible because fruit growth predominates over shoot growth due to high promoter hormone levels. Production of 
ABA under stress conditions in the shoot results in shoot growth cessation at a time when fruit development requires little water consumption and fruit growth has an advantageous position because of promoter hormones produced in the fruit.

Each phonological phase of growth and development has definable relationships to environmental conditions with characteristics and limits that can be determined and outlined with mathematical precision. The Utah Chill Unit and Growth Unit models are examples of such models. While annual plants may not depend on environmental changes for phase change, it is certain that biennials and perennials do. In most cases, the environmental cues are conditions that approach or exceed the current phenology stress limits. Indeed, such cues are often stresses during the current phase and may be physiological forces for phase change. In many cases, stressinduced plant development conditions the plant for the next phase and may partially determine the timing and intensity of that phase. While annual plants may reach their maximum genetic yields in a stressless environment, biennials and perennials require stresses to complete their cyclical growth patterns.

\section{Literature Cited}

Acevedo, E., T.C. Hsiao, and D.W. Henderson. 1971. Immediate and subsequent growth responses of Maize leaves to changes in water status. Plant Physiol. 48:631-636.

Anderson, J.L., G.L. Ashcroft, E.A. Richardson, J.F. Alfaro, R.E. Griffin, G.R. Hanson, and J. Keller. 1975. Effects of evaporative cooling on temperature and development of apple buds. J. Amer. Soc. Hort. Sci. 100:229-231

Avery, G.S., Jr., P.R. Burkholder, and H.B. Creighton. 1937. Production and distribution of growth hormone in shoots of Aesculus and Malus and its probable role in stimulating cambial activity. Amer. J. Bot. 24:5158.

Bennett, J.P. and F. Skoog. 1938. Preliminary experiments on the relation of growth-promoting substances to the rest period in fruit trees. Plant Physiol. 13:219-225.

Berrie, A.M.M. 1984. Germination and dormancy, p. 440-468. In: M.B. Wilkins (ed.). Advanced plant physiology. Pitman, Marshfield, Mass.

Chalmers, D.J. and B. van den Ende. 1975. Productivity of peach trees: Factors affecting dry-weight distribution during tree growth. Ann. Bot. 39:423-432.

Chalmers, D.J. and B. van den Ende. 1977. The relation between seed and fruit development in the peach(Prunus persicaL.). Ann. Bot. 41:707714.

Chalmers, D.J. and I.B. Wilson. 1978. Productivity of peach trees: Tree growth and water stress in relation to fruit growth and assimilate demand. Ann. Bot. 42:285-294.

Chalmers, D.J., P.D. Mitchell, and L. van Heek. 1981. Control of peach tree growth and productivity by regulated water supply, tree density, and summer pruning. J. Amer. Soc. Hort. Sci. 106:307-312.

Connors, C.H.-1920. Growth of fruits of peach. New Jersey Agr. Expt. Sta. Annu. Rpt. 40:82-88.

del Real-Laborde, J.I. 1987. Estimating chill units at low latitudes. HortScience 22:1227-1231.

Digby, J. and P.F. Wareing. 1966. The relationship between endogenous hormone levels in the plant and seasonal aspects of cambial activity. Ann. Bot. 30:607-622.

Erez, A., G.A. Couvillon, and C.H. Hendershott. 1979. Quantitative chilling enhancement and negation in peach buds by high temperatures in a daily cycle. J. Amer. Soc. Hort. Sci. 104(4):536-540.

Evans, R.G. 1982. Irrigation scheduling and monitoring water requirements, p. 201-230. In: R.B. Tukey (ed.). Tree fruit water management and irrigation of tree fruits. Washington State Univ. Coop. Extn., Pullman.

Flemion, F. 1956. Effects of temperature, light and nutrients on physiological dwarfing in peach seedlings. Plant Physiol. 31. (Suppl. iii.)

Glinka, Z. and L. Reinhold. 1972. Induced changes in the permeability of plant cells to water. Plant Physiol. 49:602-606.

Hammond, M.W. and S.D. Seeley. 1978. Spring bud development of Malus and Prurus species in relation to soil temperature. J. Amer. Soc. Hort Sci. 103:655-657.

Hatch, A.H. and D.R. Walker. 1969. Rest intensity of dormant peach and apricot leaf buds as influenced by temperature, cold hardiness and respiration. J. Amer. Soc. Hort. Sci. 94:304-307.
Hatcher, E.S.J. 1959. Auxin relations of the woody shoot. Ann. Bot. 23:409423.

Jackson, D.I. 1968. Gibberellin and the growth of peach and apricot fruits. Austral. J. Biol. Sci. 21:209-215.

Kahn, A.A. 1982. The physiology and biochemistry of seed development, dormancy and germination. Elsevier Biomedical Press, Amsterdam.

Little, C.H.A. 1975. Inhibition of cambial activity inAbies balsamea by internal water stress: Role of abscisic acid. Can. J. Bot. 53:3041-3050.

Little, C.H.A. and P.F. Wareing. 1981. Control of cambial activity and dormancy in Picea sitchensis by indol-3-ylacetic and abscisic acids. Can. J. Bot. 59:1480-1493.

Luckwill, L.C. 1970. The control of growth and fruitfulness in apple trees, p. 237-253. In: L.C. Luckwill and C.V. Cutting (eds.). Physiology of tree crops. Academic, New York.

Mansfield, T.A. 1987. Hormones as regulators of water balance, p. 411430. In. P.J. Davies (ed.). Plant hormones and their role in plant growth and development. Martinus Nijhoff, Boston.

Mizrahi. Y. 1980. The role of plant hormones in plant adaptation to stress conditions. 15th Colloq. of Intl. Potash Inst. p. 75-86.

Pasternak, G.P. and L.E. Powell. 1980. Chilling requirements of apple seeds from cultivars having low and high chilling requirements for shoot growth. HortScience 15:408. (Abstr.)

Powell, L.E. 1987. The hormonal control of bud and seed dormancy in woody plants, p. 539-552. In: P.J. Davies (ed.). Plant hormones and their role in plant growth and development. Martinus Nijhoff, Boston.

Powell, L.E. and C. Pratt. 1966. Growth promoting substances in the developing fruit of peach (Prunus persica L.) J. Hort. Sci. 41:331-348.

Reinders-Gouwentak, C.A. 1941. Cambial activity as dependent on the presence of growth hormone and the non-resting condition of stems. Proc. Ned. Akad. Wetensch. Amsterdam 44:654-662.

Richardson, E.A., S.D. Seeley, and D.R. Walker. 1974. A model for estimating the completion of rest for 'Redhaven' and 'Elberta' peach trees. HortScience 9:331-332.

Richardson, S.D. 1959. Bud dormancy and root development in Acer saccharinum, p. 409-425. In: K.V. Thimann (ed.). The physiology of forest trees. Ronald, New York.

Rom, R.C. and E.H. Arrington. 1965. The effect of varying temperature regimes on degree-days to bloom in the Elberta peach. Proc. Amer. Soc. Hort. Sci. 88:239-244.

Seeley, E.J. 1975. Application of instrumental gibberellic acid analysis techniques: With special reference to gibberellic acids in after-ripening peach seeds and developing flower buds. PhD Diss., Utah State Univ., Logan.

Seeley, S.D. and H. Damavandy. 1985. Response of seed of seven deciduous fruits to stratification temperatures and implications for modeling. J. Amer. Soc. Hort. Sci. 110:726-729.

Seeley, S.D. and L.E. Powell. 1981. Seasonal changes of free and hydrolyzable abscisic acid in vegetative apple buds. J. Amer. Soc. Hort. Sci. 106:405-409.

Thompson, M.M., D.C. Smith, and J.E. Burgess. 1985. Nondormant mutants in a temperate tree species, Corylus avellana L. Theor. Applied Genet. 70:687-692.

Vegis, A. 1964. Dormancy in higher plants. Annu. Rev. Plant Physiol. $15: 185-224$

Wareing. P.F. 1958. The physiology of cambial activity. J. Inst. Wood Sci. $1: 34-42$

Wareing, P.F., C.E.A. Haney, and J. Digby. 1964. The role of endogenous hormones in cambial activity and xylem differentiation, p. 323-344. In: M.H. Zimmerman. (ed.). The formation of wood in forest trees. Academic, New York.

Wareing, P.F. and I.D.J. Phillips. 1978. The control of growth and differentiation in plants. Pergamon, New York.

Westwood, M.N. and H.O. Bjornstad. 1968. Chilling requirements of dormant seeds of 14 pear species as related to their climatic adaptation. Proc. Amer. Soc. Hort. Sci. 92:141-149.

Wodzicki, T.J. 1971. Mechanism of xylem differentiation in Pinus silvestris L. J. Expt. Bot. 22:670-687.

Wright, S.T.C. and R.W.P. Hiron. 1969. (+) Abscisic acid, the growth inhibitor induced in detached wheat leaves by a period of wilting. Nature (London) 224:719-720

Zajaczkowski, S. 1973. Auxin stimulation of cambial activity in Pinus silvestris: I. The differential cambial response. Physiol. Plant. 29:281-287.

Zimmerman, M.H. and C.L. Brown. 1974. Trees structure and function. Springer-Verlag, New York.

Zimmerman, W.A. 1936. Untersuchungen über die räumliche und zeitliche Verteilung des Wuchsstoffes bei Bäumen. Zeitschr. Bot. 30:209-252. 